\title{
Malinche: o poder do feminino no entrecruzamento de Literatura e História a propósito de $O$ que querem os deuses
}

\author{
Malinche: the power of the feminine at the intersection of Literature and History regarding of $O$ que querem \\ os deuses
}

\section{Dóris Helena Soares da Silva Giacomolli}

Universidade Federal de Pelotas - UFPel - Pelotas - Rio Grande do Sul - Brasil

\begin{abstract}
Resumo: Há relações entre literatura e história referentes ao entrecruzamento dos discursos histórico e literário, no âmbito de diferentes gêneros. Esse é um estudo sobre a obra literária $O$ que querem os deuses que vem recontar uma nova versão dos fatos históricos e reviver a figura de Malinche em um mundo fictício em que essa passa a habitar e a promover um intenso diálogo entre a literatura e a história, apagando as possíveis e frágeis fronteiras entre as duas, uma vez que a personagem leva com ela o tempo, os vestígios e artefatos históricos, estendendo-se por uma tênue linha que separa a realidade objetiva da realidade ficcional. Apesar dos "esquecimentos," das heterogeneidades, dos recuos e disjunções em torno da figura de Malinche pode-se perceber que o que se procura esconder sobre sua figura teve importância capital. $O$ romance $O$ que querem os deuses, ao recuperar sua memória, e ao fazê-la ultrapassar o portal entre história e literatura, permite que Malinche carregue consigo uma representação feminina que se re-constitui nas relações estabelecidas de poder.
\end{abstract}

Palavras-chave: Malinche. Literatura. História. $O$ que querem os deuses. Representação feminina.

Abstract: There are relations between Literature and History concerning the intertwining of historical and literary discourses within different genres. This is a study on the literary work What the gods want to retell a new version of historical facts and revive the figure of Malinche in a fictional world in which she begins to inhabit and promote an intense dialogue between Literature and History, erasing the possible and fragile borders between the two sciences, since this character takes with her the time, the vestiges and historical artifacts, extending by a thin line that separates the objective reality from the fictional one. In spite of the "forgetfulness" of the heterogeneities, of the setbacks and disjunctions around the figure of Malinche we can perceive that what someone tried to hide about her figure had capital importance. The novel What the Gods Want, in recovering her memory, and in making it surpass the portal between history and literature allows Malinche to carry with her a feminine representation that re-constitutes in established relations of power.

Keywords: Malinche. Literature. History. What the gods want. Female representation. 


\section{Introdução}

Havia uma mulher ameríndia que foi a tradutora de Hernán Cortéz, o "conquistador" espanhol e o ajudou a vencer os mexicas ${ }^{1}$, povo nômade, que segundo a mitologia, saiu do norte em busca de terras melhores. O ponto em que essa população deveria radicar-se seria marcado pela presença uma águia devorando uma serpente sobre um cacto. Ao chegarem a esse lugar pré-determinado, essas pessoas fundariam uma cidade de nome Tenochitlán. Após a derrota infligida pelos espanhóis chefiados por Hernán Cortéz, com a ajuda dessa mulher que passou a ser chamada de Malinche, a cidade do México foi erguida sob os destroços dessa civilização nativa.

Logo ao chegar, Cortéz encontrou Malinche, uma entre vinte mulheres escravas dadas aos espanhóis pelos nativos de Tabasco em 1519. Essa nativa, fluente no idioma do qual Cortéz precisava, tornou-se tradutora e acompanhou Cortéz tão de perto que códices astecas mostram sua imagem retratada quase sempre ao lado de Cortéz. Mais tarde, ela se tornou amante de Cortéz e deu à luz seu primeiro filho, Martín. Estranhamente, sua figura quase não é mencionada nos relatos espanhóis.

Malinche, chamada por muitos de La lengua, recebeu o nome espanhol de Marina. $^{2}$ Linguistas determinaram que Malintzin era a pronúncia da língua nahuatl para Marina e os falantes desse idioma substituíram o $r$ espanhol com um $I$, de modo que o nome se tornou Malina. Os falantes nahuatl acrescentaram então a esse nome, um final que significava a palavra dona:-tzin. Este final é semelhante ao espanhol Doña, que também é usado como sinal de respeito. Assim como Díaz del Castillo (2005) chamou a tradutora Doña Marina, os falantes náhuatl a chamaram de Malintzin. Da mesma forma que os espanhóis tiveram dificuldade em pronunciar o náhuatl- $t z$, então mudaram para -ch, ao mesmo tempo que deixaram cair no silêncio o $n$ no final de seu nome. Dessa maneira, Malinalli se tornou Doña

\footnotetext{
${ }^{1}$ Nome original dos astecas.

${ }^{2}$ Mallinali. Erva ou feno. Um dos dias do calendário, considerado nefasto.
}

Marina, Malintzin e Malinche de uma só vez, La lengua, que tinha $o$ poder de transformar pela palavra, ironicamente, por meio de uma série de erros de tradução ou de pronúncia, pode ser chamada de várias maneiras. Giacomolli (2018) assim apreende a confusão do nome da personagem Malinche:

Os mensageiros se entreolharam, incrédulos. O mais velho deles falou, não sem hostilidade na voz:

- E por que devemos confiar em você? Está do lado dele, diz o que ele manda, Malintzin.

Ao referir-se ao nome de Marina usou a palavra, tzin, dona, ao final do nome. Não conseguiu pronunciar o $r$ e o novo nome soou Malintzin.

Dona Marina, Malintzin, ela sorriu por dentro, mas permaneceu com a expressão muito séria; sim, essa sou eu, a emissária do deus Quetzalcoatl: Malintzin. (GIACOMOLLI, 2018, p. 224)

Em O que querem os deuses, a autora pede passagem e pelos caminhos da literatura acompanha a história onde as mulheres nativas são retratadas como objetos de uso para os espanhóis:

As nativas acenaram para ele, dando risinhos alegres. - Por que não? - pensou ele. Fez sinal a elas que correram para ele. Deitaram-se sob o luar; os corpos delas lhe lembraram de Malinche. - Todas essas nativas se parecem refletiu Cortés. Tocou o seio de uma delas sem a forma dos seios das espanholas. Nunca ouviram falar de espartilhos. Os corpos delas têm a forma que a natureza lhes dá. Mas eram bons corpos, serviam. (GIACOMOLLI, 2018, p. 277)

No decorrer da escrita, entretanto, algumas personagens mulheres vão assumindo as rédeas de seus destinos.

Os impasses na convivência entre os sexos, o machismo, as relações de poder, a desconsideração e o desprezo pelo feminino se impõem com a aceitação da sociedade como um todo, é isso não é algo recente na história da humanidade. Certamente, as mulheres eram assim vistas por Cortéz, se pode perceber, mais de uma vez, em $O$ que querem os deuses, o desprezo de Hernán Cortéz às mulheres indígenas e à própria Malinche: "Não pretenda mais do que isso. Sou um europeu, pertenço a uma civilização superior, você não vê? Você é uma nativa, apesar de ter sido batizada.

Malintzin. Nome indígena de Doña Marina, La Malinche. 
Não pensou que eu me casaria com você, pensou?" (GIACOMOLLI, 2018, p. 306) O romance vem problematizar relações intersexuais que se manifestam entre homens mulheres e que têm um componente de poder e hierarquia.

A figura feminina é subalterna ao homem e, por não ter voz nem vez, atuava passivamente diante da sociedade espanhola medieval. Essa mesma visão estereotipada foi trazida pelos espanhóis nos navios e agravou-se ao entrar em contato com as indígenas, tendo seu valor duplamente desvalorizado, em sua condição de mulher, agravada pelo fato de serem indígenas, o que as tornava objetos de troca, mercadorias, presentes a serem oferecidos como regalos. No romance, desde as primeiras mulheres que mantem intercurso com Hernán Cortez, como a espanhola casada, ainda na Espanha ou a nativa de Azua de Compostela, todas são tratadas como coisas: "Uma noite levou-a para sua rede, sem grandes emoções. Serviu-se dela para saciar-se como quem usa a comida para matar a fome." (GIACOMOLLI, 2018, p. 120)

Mas, ao longo deste romance, a autora vai conduzindo as personagens femininas, fazendo com que elas atuem significativamente, transformando seus destinos, a despeito da voz masculina que procurava manipulá-las. Isso acontece com as duas figuras femininas principais, Catalina e Malinche. Catalina, espanhola, manipula a situação, conseguindo que Hernán, sem alternativa, acabe se casando com ela, conseguindo aquilo que viera buscar: um marido. Por sua vez, a figura de Malinche é tratada com mais complexidade, uma vez que essa personagem passou à História afundada em ambiguidade axiológica oscilante entre a positividade de ser mãe do primeiro mestiço e a negatividade de ser mulher, traidora de sua terra e de seus habitantes originários. A dificuldade quanto à origem de seu nome se reflete no enigma que rodeiam seus antecedentes e status. Cortéz, homem em torno do qual o nome de Malinche orbita, só a menciona duas vezes em suas cartas. No primeiro caso, ele simplesmente se refere a ela como sua tradutora, "uma índia". No segundo caso, ele a chama de Marina, sem o pronome de tratamento
"Doña", normalmente usada por homens espanhóis ao discutir mulheres virtuosas e de classe alta. Como se interpreta isso? Será que ele a desconsiderava por causa de suas origens: mulher-escrava-indígenadada-a-ele? Ele a reificara como objeto de uso, independentemente de sua classe social? Teria Hernán Cortéz achado que apontar a relevância de uma personalidade feminina nas suas ações e conquistas não seguiria as normas de bom procedimento estabelecidas em um mundo dominado pelo sujeito masculino? Ou, ainda, seria Hernán Cortéz muito vaidoso para mencionar Malinche, assim como evitava conferir valor aos nativos, milhares de totonacas e tlaxcaltecas, que emprestaram seus guerreiros para lutar contra os astecas, ao lado dos espanhóis? Foi por acaso que Cortéz não os menciona, ressaltando que a "conquista" se deu com a subjugação de milhares de astecas por duas ou três centenas de espanhóis apenas?

Os nativos de Tlaxcala que formaram uma aliança com Cortéz contra Montezuma reconheciam a importância de Malinche: chamavam tanto ela quanto Cortéz pelo mesmo nome: Malintzin. Talvez até mesmo dessem mais autoridade a ela, pois chamavam o estrangeiro que chegava, pelo nome da mulher que Ihe traduzia as palvras, ou talvez, (quem sabe?) emprestasse palavras a ele. Julgariam, talvez, que Malinche era dona de Cortéz, que exercia influência sobre ele.

De acordo com Bernal Díaz del Castillo (2005), ela falou com emissários de Montezuma em seu idioma nativo nahuatl e apontou para Cortéz como o líder dos espanhóis e a quem Montezuma deveria dirigir-se.

Por que Montezuma aceitou receber Cortéz? Por que teria recebido o estrangeiro que chegava e os deixou entrar em sua cidade, sem defesa ou precaução? Teria acreditado, como sugerem alguns autores, ser esse forasteiro o deus Quetzalcoatl, o "Serpente emplumada," que havia partido há muito tempo para o leste e que prometeu que um dia retornaria? O que o levou a crer nisso? Talvez tenha sido levado a acreditar nisso por alguém, talvez pela própria Malinche, que conhecia de perto as crenças 
deste governante e os anseios desse povo? Quem melhor que ela conhecia o povo, a língua, os mitos, a religião, as crenças, a capacidade intelectual de seu povo e a intenção dos forasteiros, já que aprendera sua língua e ouvia o que conversavam? O fato é que os espanhóis entraram em Tenochtitlan, sem nada que os impedisse, com suas armas e seus cavalos para encontrar o poderoso Montezuma, o que por si só é um fato muito curioso, que nada explica: por que um governante com tanto poder quanto o tatloani asteca aceitou receber dentro de sua corte de poder, desarmado, o estranho que fora parar ali sem uma razão específica, que chegava sem nada para oferecer em troca, e deixou que carregassem com eles, para dentro de sua cidade, suas armas? Certamente Malinche teve mais influência do que os espanhóis anunciaram em suas cartas e testemunhos posteriores. Para mostrar que eram aliados dos espanhóis, os tlaxcaltecas pintaram um códice ${ }^{3}$ e nele, a figura de Malinche aparece constantemente. Isso é uma indicação, por si só, de que os dois faziam suas aparições públicas, constantemente em conjunto e que os Tlaxcaltecas consideravam que Hernãn sofria considerável influência de Malinalli, La Malinche. Se não fosse por esses códices, mais silêncio e esquecimento existiriam sobre o nome de Malinche.

Os historiadores nunca puderam saber com certeza quem era exatamente Malinche porque os registros são silenciosos. Ela teve seus registros biográficos esquecidos e suas ações desconsideradas ou apagadas contundentemente, para que o seu valor na "conquista" fosse minimizado, uma perversa forma de violência perpetrada contra as mulheres, através dos séculos, mas mesmo assim, parece que ela teima em reviver e clamar por seu nome em obras como $O$ que querem os deuses, pois "o que está proibido ao historiador, está ao alcance do romancista." (ROBIN, 2016, p. 98) O único relato histórico detalhado feito por espanhóis vem do companheiro de Cortéz, Bernal Díaz

\footnotetext{
3 Lienzo de Tlaxcala é um documento que pretendia mostrar ao rei da Espanha, Carlos V, toda a ajuda dada pelos tlaxcaltecas aos espanhóis nos episódios da conquista. Sua produção data do século XVI e foi feita a partir da memória dos acontecimentos ocorridos entre 1519 e 1521, quando Cortés deu início à sua
}

del Castillo. Bernal Díaz (2005) descreveu-a como "de boa aparência, inteligente e auto-confiante." Em outros lugares, ele afirma que "ela era uma grande princesa, a filha de Caciques como era muito evidente em sua aparência." (DÍAZ DEL CASTILLO, 2005). Ele escreveu que seus pais eram "senhores e caciques" de uma cidade chamada Paynala. Seu pai morreu quando ela era jovem e quando sua mãe se casou de novo, ela deu, ou vendeu, La Malinche a alguns índios de Xicalango. Alguns outros dizem que era uma princesa raptada:

A historiografia tradicional tratou La Malinche de maneira ambivalente, como traidora ou como heroína de sua gente. Sua imagem muda de acordo com o tempo e as ideologias políticas. Sobre ela têm sido elaboradas diversas versões populares que perduram até a atualidade. Trata-se de uma personagem que está encravada na memória mexicana como um símbolo maldito e ambíguo, o arquétipo da traição à pátria e, ao mesmo tempo, a mãe dos mexicanos, o paradigma da mestiçagem. (SEGER, 2014, p.15)

De acordo com Díaz del Castillo, casou-se com um dos homens de Cortéz, Juan Jaramillo, durante a expedição de Honduras que se seguiu à conquista de Tenochtitlan. Por que ela fez isso não está claro, mas além de seu filho Martin, que ela teve com Cortéz, ela teve uma filha, Maria, que foi criada e batizada como filha de Jaramillo. Para o historiador oficial de Cortéz, Bernal Díaz de Castillo,(2005) Dona Marina era de origem nobre e o membro mais importante da comunidade indígena depois de Montezuma. Além de ser intérprete, Dona Marina trabalhou pela conversão dos indígenas ao cristianismo; o evento mais importante, descrito por Castillo, é a traição de Dona Marina, pois esta denuncia a conspiração de Choluta, o que leva Cortéz a uma ação violenta contra os indígenas que foram mortos barbaramente; nas crônicas e nos códices indígenas a representam La Llorona, além de intérprete e traidora. Em algumas tradições populares ela aparece como a Virgem. São muitas e paradoxais

aventura na América. Ele foi confeccionado em estilo pictográfico, composto por cerca de noventa e uma imagens, em vinte e duas das quais La Malinche se encontra representada. A "lengua", tal como eram chamados os tradutores, aparece muitas vezes em destaque. (SEGER, 2014, p.12) 
as representações feitas de Malinche. Com base em cartas de seus filhos encontradas em arquivos espanhóis, ela morreu entre 1551 e 1552. Outras fontes dizem que ela teria morrido em 1529. É muita disparidade entre essas informações, se considerarmos que se trata de uma figura que exerceu influência entre o círculo social pelo qual transitou.

Quase nada mais é conhecido sobre ela.

\section{História e a literatura}

O que é história e o que é ficção? White (1994) estabelece uma estreita relação entre historiografia, literatura e textos de ficção. A literatura pode apresentar narrativas de ficção como se fossem reais, trazendo personagens verdadeiros para a ficção literária. O que querem os deuses permite, além de um desvelamento de traços característicos da sociedade mexicana e dos sujeitos a ela pertencentes, uma distinção e uma aproximação entre história e ficção já que segundo White (1994) imprecisa essa distinção. Há semelhanças entre a narrativa histórica e o relato ficcional uma vez que os dois discursos estruturam-se da mesma maneira e da mesma maneira lhes é dado sentido. A afinidade entre a história e a literatura de ficção vem se tornando cada vez mais fecunda e é amplamente empregada pelos historiadores hodiernos, nomeadamente aqueles que investigam os meios culturais e sociais das relações humanas. Dito isso, cabe lembrar que a literatura vem se mostrando um componente enormemente expressivo no processo de escrita da História.

Vendo assim, é possível ver Malinche como personagem e objeto cultural, passível de ser investigado num ato de recontar a história oficial da colonização do povo asteca, mesclando ficção e realidade, demonstrando como foram estruturados os mitos. Tantas controvérsias e tantas questões ocultas ou disfarçadas quando se refere à personagem Malinche, desperta a curiosidade. O romance aqui analisado, além de reescrever, sob uma perspectiva diferente, a história da escrava indígena que passou por um processo de transculturação e tal qual a história o faz, muitas vezes, juntou conteúdos inventados aos conteúdos descobertos, se fez livre para acrescentar detalhes e reviver essa figura, pois se "os historiadores culturais têm de praticar a crítica das fontes, perguntar por que um dado texto ou imagem veio a existir, e se, por exemplo, seu propósito era convencer o público a realizar alguma ação” (BURKE, 2005, pg. 32-33), o romancista pode ir por caminhos mais herméticos. Havendo muitas controvérsias sobre a representação da figura de Malinche que chegou aos dias atuais, $O$ que querem os deuses, aproximando ficção e realidade, mostra a crueza das personagens históricas, a cultura asteca e o período de dominação espanhola, sem deixar de inserir uma crítica feminista que vem a ser aclaradora da condição feminina. A figura histórica de La Malinche permanece iconicamente potente, apesar de ter ocupado um lugar marginal na História tradicional. Dona Marina, Marina, Malinali ou Malinche é mais um mito que se misturou às lendas astecas que propriamente um personagem histórico. Uma vez que os limites entre as fronteiras da literatura e da história foram encurtadas, se não abolidas, tornando-se imprecisas, indefinidas e inexatas, um portal foi aberto para deixar as narrativas tão próximas, que o trânsito de personagens foi permitido. No romance literário já referido, temos a presença de narrativas que nos propiciarão elementos concretos para a análise da relação literatura e história, uma vez que qualquer narrativa representará o passado, e essas formas literárias estabelecem um diálogo claro com a história.

As representações literárias vêm no sentido de verificar aspectos de verossimilhança, pois representar literariamente é, também, representar socialmente a comunidade. Hayden White (1994) em O texto histórico como artefato literário nos diz que os procedimentos envolvidos na escrita da narrativa histórica estão muito próximos de qualquer narrativa, sobretudo na tradição da expressão literária e que o conteúdo é extraído da maneira como a história é contada, ou seja, por sua organização textual. (WHITE, 1994) O autor afirma que narrativas históricas são ficções verbais com conteúdos inventados que se juntam aos conteúdos descobertos e têm, por isso, mais semelhanças com a literatura do que com 
quaisquer outras ciências. Hayden White (1994) enfatiza que não é de toda narrativa que a história se aproxima, mas apenas da narrativa literária:

Houve uma relutância em considerar narrativas históricas como aquilo que elas realmente são: ficções verbais cujos conteúdos são tanto inventados quanto descobertos e cujas formas têm mais em comum com os seus equivalentes na literatura do que com os seus correspondentes nas ciências (WHITE, 1994, p. 98)

Hayden White (1994) concebe a história como ficção, um discurso narrativo em prosa que combina acontecimentos presumivelmente ocorridos no passado; à história carece cada vez mais debater o que é histórico, de modo que:

[...] enquanto um historiador pode entender que é sua tarefa reevocar, de maneira lírica ou poética, o 'espírito' de uma época passada, outro pode presumir que lhe cabe sondar o que há por trás dos acontecimentos a fim de revelar as 'leis' ou os 'princípios' de que o 'espírito' de uma determinada época é apenas uma manifestação ou forma fenomênica. Ou, para registrar uma outra diferença fundamental, alguns historiadores concebem sua obra primordialmente como uma contribuição para a iluminação de problemas e conflitos sociais existentes, enquanto outros se inclinam para suprimir tais preocupações presentistas e tentam determinar em que medida um dado período do passado difere do seu, no que parece ser um estado de espírito bem próximo daquele do 'antiquário' (WHITE, 1994, p. 20)

White afirma que um determinado historiador ao fazer um exame da história, "provavelmente será adepto de uma ou outra de suas seitas e, por conseguinte, tendencioso." (WHITE, 1994, p. 97) A literatura tanto quanto a história

\begin{abstract}
"se desenvolvem por meio de produção de clássicos, cuja natureza é tal que não podemos invalidá-los nem negálos, a exemplo dos principais esquemas conceituais das ciências. E é o seu caráter de não-invalidação que atesta a natureza essencialmente literária dos clássicos históricos." (WHITE, 1994, p.106).
\end{abstract}

Enquanto construção discursiva, literatura e narrativa imaginada, o romance deixa entrever 0 caráter histórico que perpassa a obra literária.

\section{A teia que emaranha o verdadeiro e o falso}

A literatura é uma poderosa "força de iniciação na vida, complexa e variada, nem sempre desejada pelos educadores, pois seus padrões nem sempre elevam ou edificam", e "livremente em si o que chamamos o bem e o que chamamos o mal, humaniza em sentido profundo porque faz viver" (CANDIDO, 2004, p. 176). A literatura tem seu lugar ligado à sua complexidade por ser obra do caráter humano e vem da alguma maneira substituir o muito da memória histórica do homem que se perdeu por meio de grandes catástrofes, causas de grande destruição de valiosos suportes materiais da memória. Nas últimas décadas, por todo o mundo, o passado retorna em forma de discurso de memória e Régine Robin (2016) se pergunta qual seria a forma ideal para que a memória retornasse sem que para isso tivéssemos que cair na armadilha dos "abusos de memória." Não estamos livres da presença do passado, ele retorna sobre nós. "A bobina do passado está em permanente rebobinação," (ROBIN, 2016, p. 25) diz a autora e pega emprestada a frase de Jean-Cristophe Bailly: "Era como se o passado nevasse sobre nós" (ROBIN, 2016, p. 25)

Nos diz Régine Robin (2016) que o passado não é livre, que ele é gerido, regido, preservado e que sob a exigência de determinado momento nós o fazemos retornar e que aqueles episódios que não foram inscritas na história oficial retornam, misturadas às lendas, à ficção, até mesmo reaparecem meio deformadas, "se enriquecem com elementos advindos de outras épocas." (ROBIN, 2016, p. 32)

A autora fala da dificuldade que têm os historiadores e que por isso adotam a noção de recalque, já que "não é possível compreender o trabalho imemorial sem considerar as camadas do tempo, esses "esquecimentos" eficazes que permanecem como bases, essas heterogeneidades, esses recuos e disjunções" (ROBIN, 2016, p. 36)

Segundo ela, "o excesso de memória seria da ordem da compulsão de repetição interditando toda a reconciliação com o passado e toda distância crítica. $A$ falta de memória seria também da ordem do recalque, pronta para voltar a atormentar um tecido social mal estabilizado e que acreditava" poder fazer uma 
economia de sua relação com o passado. "(ROBIN, 2016, p. 37)

Régine Robin não acredita em reconciliação completa com o passado, nem memória justa, assim como também não crê em uma separação total. O que há são outros caminhos para identificar o que existe nos problemas de memória, em sua história; para as sociedades raramente cedem à melancolia, então a escolha nunca se dá entre essa e o trabalho de luto. Em toda a parte, há encontros perdidos com a história, e por isso ela prefere falar em ritmos de memória e dizer que o trabalho de memória é difícil e que

no debate, em conflito, está longe de
triunfar, está sempre a retornar e
sempre tomado em uma conjuntura em
que ele próprio está em questão,
preenche uma função social, é mais ou
menos instrumentalizado - talvez seja
impossível que seja diferente -
politicamente, culturalmente,
historigraficamente. (ROBIN, 2016, p.
40)

Diz Robin que o presente não é um tempo homogêneo, mas articulações de temporalidades diferentes; o passado retorna: "Os velhos antepassados, já mortos, vinham para ensinar a todos o que tinham aprendido; falavam pela boca dos velhos que gostavam de ensinar os jovens que gostavam de ouvi-los, de aprender com eles." (GIACOMOLLI, 2018, p. 17)

Destruições naturais ou as provocadas pelo homem, revoluções e guerras, resultam em apagamentos de memória. Com isso se dá as restaurações e as renovações; a restauração se dá após a demolição. "Paisagens rurais e urbanas são assim totalmente ou parcialmente reconfigurada, suscitando nostalgias e ou ilusões de autenticidade" (ROBIN, 2016, p. 82)

O passado pode escapar a alguns, exceto aos historiadores, aos que se debruçam sobre ele, aos pesquisadores e aos romancistas, ele volta. Uma sociedade mantem tabus e silêncios que podem apagar o passado: "Um acontecimento pode se produzir sem testemunha, sem resto, sem ruína, sem nada que possa revelar que houve um acontecimento." (ROBIN, 2016, p. 85) O nazismo assim agiu ao tentar, não só aniquilar os judeus, mas também apagar os vestígios tanto desse crime como da existência dessa população. Os romanos também agiam assim quando queriam eliminar vestígios de um imperador, apagando seus decretos, suas leis, seus rastros e vestígios; sua memória ficava abolida.

Quando não se presta atenção, quando não se lembra, desaparecimentos não são percebidos. É importante relembrar o extermínio dos campos de concentração, das vítimas das ditaduras, mas não só; há outras populações dizimadas que merecem ser lembradas, há indígenas que foram dizimados graças à sua ingenuidade a ao seu despreparo frente ao avanço do inimigo que chegava com outros avanços, outras armas, outros vírus, desconhecidos, mortais.

\begin{abstract}
A luta, quase vencida, degenerou-se em esgotamento e no suplício da sede. A vida tornou-se atroz. Os astecas rastejavam a noite para buscar raízes, ervas e folhas. Os espanhóis davam o bote; o bando de mulheres, velhos enfraquecidos e crianças que nem tinham tempo de chorar eram abatidos e aumentavam o número de corpos sangrentos que salpicava a cidade de Tenochtitlán. A cidade era um espetáculo macabro. Por todo lugar, se viam escombros, corpos estirados, decapitados ou sem os membros, empilhavam-se num monte repugnante; outros, já cobertos de vermes, jaziam a céu aberto. (GIACOMOLLI, 2018, p. 299)
\end{abstract}

Esse genocídio, também devem ser lembrados, suas histórias recontadas. Os clamores amortecidos desses mortos estao pedindo para serem escutados.

Vem daí, dessa necessidade de vozes apagadas serem ouvidas, segundo Robin(2016), uma "obstinação do fragmento, da peça do quebra-cabeça, da lembrança, do pedaço de papel, do objeto e também das listas e inventários." (ROBIN, 2016, p. 92) O historiógrafo e o conservador de fragmentos serão um baluarte contra o esquecimento. Assim o são os romancistas, que de um nome esquecido, talvez intencionalmente apagado, fazem renascer uma pessoa, dão-lhe rosto, família, motivos, desculpas e importância.

Tantos seres passaram pelo mundo e deles não restou nada, nem uma lápide ou um epitáfio. Completamente esquecidos, anônimos, sem 
importância. Robin (2016) refere-se ao desaparecimento completo dos anônimos, daqueles que são esquecidos quando uns poucos rastros deixados se extinguem. Esse desaparecimento é o destino comum de grande parte, a grande maioria da humanidade. "Somente a curiosidade de um historiador e ou de um romancista pode dar vida novamente aos desconhecidos, anônimos e esquecidos." (ROBIN, 2016, p. 96)

Um escritor pode fazer reviver um anônimo, um esquecido, que muitas vezes deixa quase nada de si, um nome, uma profissão. Se um escritor não vier salvá-lo do anonimato ele será completamente esquecido, como se nunca houvesse existido. "Quando não sabemos, imaginamos." (ROBIN, 2016, p. 98) O que faltar, os espaços, os vácuos, pode ser completados pela fantasia e reflexão desse escritor. "O crível, o plausível, no lugar da verdade" (ROBIN, 2016, p. 98) A imaginação pode vir a complementar os fatos, vestígios podem ser recuperados. Um romance, ao ser escrito, torna possível a criação de todo um mundo, com seu próprio tempo, espaço e tempo específicos. Um romance histórico ao ser escrito, não cria um tempo, um mundo; revive-o, não cria um tempo, restaura-o, como se fosse uma máquina do tempo, é capaz de levar pessoas até esse tempo, reviver pessoas, recuperar o espaço tal qual era. "Evocava as dores do passado, das paradas e dos novos recomeços, sempre malignos, sempre escuros, sempre doloridos. "GIACOMOLLI, 2018, p. 17) Os romancistas e os arquivistas podem ser acumuladores de vestígios, podem manipulá-los e transmiti-los. "Mestres da memória por seu trabalho [...] são também mestres do tempo, mestre das cidades dos mortos e dos vivos, portanto da boa ordem do mundo." (ROBIN, 2016, p. 104) Esse romance traz Malinche de volta, e com ela seu nome e seu passado, suas dores e aflições, faz uma desconhecida sair do esquecimento, faz renascer um anônimo, no seu tempo e espaço, faz com que uma história possa, outra vez, ser escrita, ser lembrada, seus detalhes ressignificados e percebidos.

Ao escrever sobre o passado e as relações humanas e suas verdades, não há como prescindir do sujeito, de suas emoções, do aspecto individual na pesquisa.

O que é então a verdade? Um exército móbil de metáforas, metonímias, antropomorfismos, em resumo: uma suma de relações humanas que foram reforçadas poética e retoricamente, que foram deslocadas e embelezadas e que após um longo uso, parecem a um dado povo, sólidas, canônicas e vinculatórias. As verdades são ilusões das quais se esqueceu a natureza evasiva, são metáforas que se esgarçaram e perderam toda forma sensível, são moedas cujas imagens se apagaram e são levadas em consideração apenas como metal e não mais como moedas (NIETZSCHE apud GINZBURG, 2002, p.24).

Carlos Gizburg (2002) disse: "A história é um romance que se pode provar." O conteúdo de $O$ que querem os deuses não se pode provar, pois é literatura, ficção verbal e não somente história, mas se narrativas históricas são ficções verbais com conteúdos inventados que se juntam aos conteúdos descobertos e têm, por isso, mais semelhanças com a literatura do que com quaisquer outras ciências, como não dizer que foi assim que se passaram os fatos? A vida faz-se arte, a história faz-se literatura e a literatura faz-se história. São histórias que se passaram há muito tempo atrás e que deixaram pistas, que são contadas por homens e mulheres, historiadores, pesquisadores e romancistas com um propósito, de contar uma verdade, reforçando-a poeticamente, fazendo com que venha à tona, encoberta e disfarçada com metáforas, metonímias, sentimentos, emoções, pensamentos, ações e comportamentos, para apresentar uma sinopse das relações humanas.

A história está próxima da retórica, ainda que isso não abstenha a história do compromisso de trazer à tona a explicação dos homens no tempo. A literatura está imersa na retórica, mas isso também não a exime de procurar o crível, de procurar ilustrar os homens no tempo, de revivê-los, de explicá-los, de procurar as razões por detrás de seus atos. Ao pesquisador, ao historiador e ao romancista foram deixados os mesmos indícios, os mesmos rastros, os mesmos vestígios, as mesmas testemunhas. O que pode diferir, na hora de contar uma história é a maneira de percebê-la, o aspecto subjetivo de quem decide contá-la. 
Após tanto tempo, após tantos ventos e tanta areia que cruzou o deserto do México, como ter certeza de que não foi assim que se passou? Que Malinche não foi uma figura feminina que sabia o que estava fazendo, que direcionou sua existência para o homem que chegava e que poderia tornar seu nome conhecido, importante? Tirá-la da condição de mercadoria, de objeto de troca, da condição de regalo, de coisa? As verdades são miragens, alucinações, das quais se esqueceu a natureza evasiva. Como garantir que a História está correta e a literatura é ilusória se são tão próximas, se são ambas ficções verbais? Ainda que a história tenha um compromisso com a verdade, isso por si só não a afasta da literatura, embora esta se volte para subjetividade humana e represente seus sentimentos e ideais, não se pode ignorar que a história está intrinsecamente ligada ao tempo e ao homem, e que portanto, o conhecimento histórico também está sujeito a aspectos subjetivos. A literatura se importa com a verdade desses sentimentos e ideais, com a veracidade com que os reporta, e precisa fazer com que o objeto de sua verdade tenha que tocar o seu destinatário e que ambos, objeto e destinatário são os mesmos: o homem.

Historiadores, romancistas, pesquisadores, arquivistas são todos acumuladores de vestígios, vestígios esses passíveis de serem manipulados e transmitidos para dar a conhecer histórias antigas, reviver um anônimo, fortalecer uma mulher, redimir um culpado, culpar um inocente, relembrar um esquecido, fortalecer um fraco, relembrar seus deuses, seus antepassados:

- Acocoramos num lugar antigo e sagrado, espalhamos nossos totens, conclamamos as forças dos antepassados, fizemos as preces e rituais e pedimos aos espíritos que ali haviam vivido para fazê-los parar. Assim dissemos:

- Somos gratos aos nossos pais antepassados que nos deram a vida e a força para honrar seus nomes. Agradecemos aos deuses que se sacrificaram e morreram para que pudéssemos estar aqui, neste lugar sagrado da floresta. Agradecemos suas energias e o sangue que deram para que nos fortalecêssemos. (GIACOMOLLI, 2018, p. 231)
Esses que escrevem, que reviram fontes, que pesquisam, que salientam os indícios e que recolhem e emendam os fragmentas são os únicos capazes de reviver o passado, de trazê-lo à tona, revivendo suas memórias.

Assim, amalgamando literatura e história, é possível salvar do anonimato alguém que de outro modo poderia, com certeza, ser completamente esquecido, como se nunca houvesse existido.

\section{Conclusão}

Conclui-se que o romance $O$ que querem os deuses aproxima ficção e realidade tornando possível reviver e reconfigurar as personagens históricas, a cultura asteca e o período de dominação espanhola, além de se tornar possível uma crítica feminista aclaradora da condição feminina. Ao trazer as representações literárias em seus aspectos de verossimilhança, o povo asteca também foi representado, assim como foram revistos e estruturados seus mitos, esclarecidas muitas controvérsias e tantas questões ocultas ou disfarçadas quando se refere à personagem Malinche. Foram trazidas à tona, além de reescrita sob uma perspectiva diferente, a história da escrava indígena em seu processo de transculturação. Na passagem da história para a literatura, fazendo coincidir a justiça, Maliche foi "empoderada" pela autora, saindo do espaço marginal que têm ocupado. O feminino apagado, cujo nome foi esquecido pelo personagem histórico Hernán Cortez em suas cartas dirigidas ao rei Carlos $V$, foi recuperado e adquiriu destaque essencial e o poder que certamente teve, ao traduzir as palavras de contato, e que interferiu enormemente na história e nas relações entre o tatloani Montezuma e os espanhóis que chegavam. Cortéz soube tirar proveito do rancor que os povos dominados tinham em relação aos dominadores, mas pode ter sido Malinche quem the esclareceu sobre os conflitos existentes na terra desconhecida em que Hernán Cortéz aportava.

Resta dizer que a literatura contribuiu imensamente no processo de escrita da História, colaborando para resgatar personagens das margens 
da historiografia oficial, nomeadamente Malinche, que teve seu nome quase apagado para que os homens que valendo-se do direito do mais forte, tivessem os seus nomes aclamados como conquistadores, para que alcançassem títulos e fossem relembrados em datas comemorativas. As provas que faltam, as evidências que foram apagadas, os retalhos que foram perdidos, a vértebra perdida para completar 0 esqueleto, a imaginação pode preencher: - Quando ignoramos os detalhes, completamos, quando não temos certeza, imaginamos. Sim, o que foi perdido, as cavidades, os espaços em branco, os orifícios vazios podem ser completados pela fantasia e imaginação daquele que escreve. O possível, o que poderia ter sido, o razoável, o admissível, o plausível, vem preencher o que poderia, ou pode, ser verdade. A fantasia pode vir a completar os fatos. E no final da leitura, um mundo poder surgir, completo, real, seus personagens ganham forma, vida, sentimentos e postam-se críveis, inteiros, aos olhos e mente do leitor.

\section{Referências}

BURKE, Peter. O que é História Cultural? Tradução de Sérgio Goes de Paula. Rio de Janeiro: Jorge Zahar, 2005.

CANDIDO, Antonio. $\mathbf{O}$ direito à literatura. In: Vários Escritos. Rio de Janeiro: Ouro Sobre azul/ São Paulo: Duas Cidades, 2004, p. 169-191.

DÍAZ DEL CASTILLO, Bernal. Edición a partir de: Díaz del Castillo, Bernal. Historia verdadera de la conquista de la Nueva España. Tomo I. Madrid: Imp. de Don Benito Cano, 1795. Biblioteca Saavedra Fajardo, 2005

GIACOMOLLI, Dóris. O que querem os deuses. Rio Grande do Sul, 2018.

GINZBURG, Carlos. Relações de força: história, retórica e prova. São Paulo: Cia das Letras, 2002.

ROBIN, Régine. A memória saturada. SP: Campinas: Unicamp, 2016.

SEGER, Magda Fabiane. La Malinche, D. Marina: a "lengua" de Cortéz segundo o "Lienzo de Tlaxcala" São Leopoldo, 2014. Disponível no link: http://www.repositorio.jesuita.org.br/handle/UNISI NOS/4253

WHITE, Hayden. O texto histórico como artefato literário. In: Trópicos do discurso: ensaios sobre a crítica da cultura. São Paulo: EDUSP, 1994. [pp. 97-116].

SOARES DA SILVA GIACOMOLLI, Dóris Helena. Malinche: o poder do feminino no entrecruzamento de Literatura e História a propósito de $\mathrm{O}$ que querem os deuses. Signo, Santa Cruz do Sul, v. 45, n. 84, nov. 2020. ISSN 1982-2014. Disponível em: <https://online.unisc.br/seer/index.php/signo/ article/view/12525>. doi:https://doi.org/10.17058/signo.v45i84.125 25. 